\title{
CONCEPÇÕES DE EDUCAÇÃO AMBIENTAL EM MÚSICAS REGIONAIS PARAENSES
}

\author{
Lucimar de Oliveira Nazaré ${ }^{1}$ \\ Raynon Joel Monteiro Alves ${ }^{2}$ \\ Altem Nascimento Pontes ${ }^{3}$ \\ Layane de Oliveira Nazaré Cavalcante ${ }^{4}$ \\ Aldo Nascimento Pontes 5
}

Resumo: Este estudo objetivou classificar as músicas regionais paraenses de dois artistas em concepções de Educação Ambiental: conservadora, pragmática e crítica. Fez-se o levantamento na discografia virtual desses cantores/compositores e como resultado obteve-se: 12 músicas relacionadas à concepção conservadora; duas, pragmática; e cinco, crítica. Essas músicas caracterizavam a natureza e visavam incutir a contemplação e a proteção natural, assim como a cultural; e enfatizavam mudanças de mentalidades e ações que podem solucionar problemas, dos mais simples aos complexos. De fato, as músicas regionais podem ser propostas pedagógicas visando a sensibilização das pessoas acerca de sua realidade local e regional e também a formação de cidadãos conscientes, críticos e atuantes na relação sociedadenatureza.

Palavras-chave: Educação; Composições Regionais; Pará; Problemas Socioambientais.

\footnotetext{
${ }^{1}$ Universidade do Estado do Pará. E-mail: lucimarnazare@gmail.com

2 Universidade do Estado do Pará. E-mail: raynon_alves@yahoo.com.br

3 Universidade do Estado do Pará. E-mail: altempontes@hotmail.com

4 Universidade Federal do Pará. E-mail: layane_nazare2006@hotmail.com

${ }^{5}$ Faculdade de Tecnologia de Indaiatuba. E-mail: aldopontes@hotmail.com
}

Revbea, São Paulo, V. 12, No 5: 41-55, 2017.

revista brasileira educação ambiental 


\section{Introdução}

No Brasil, a Educação Ambiental (EA) foi institucionalizada pelo Governo Federal, em 1973, com a criação da Secretaria Especial do Meio Ambiente (SEMA), vinculada à Presidência da República; e a Constituição Federal, em 1988, estabeleceu, no inciso VI do artigo 225, a necessidade de "promover a Educação Ambiental em todos os níveis de ensino e a conscientização pública para a preservação do meio ambiente" (HENRIQUES et al., 2007). Entende-se por EA os processos por meio dos quais o indivíduo e a coletividade constroem valores sociais, conhecimentos, habilidades, atitudes e competências voltadas para a conservação do meio ambiente, bem de uso comum do povo, essencial à sadia qualidade de vida e sua sustentabilidade (BRASIL, 1999).

Em seu conceito mais amplo, a EA surge como um processo socioeducativo que tem por finalidade reformular positivamente os atores sociais para entender a realidade e nela atuar de maneira consciente e responsável, tendo em vista a qualidade de vida individual, coletiva e do planeta (LOUREIRO, 2002). A EA existe para um bem maior, mas essa pode ser encontrada em diferentes tendências, dimensões, correntes, concepções, categorias - com complexidades variáveis. Esta pluralidade é categorizada, em distintas formas, por vários autores (SORRENTINO, 1998; SUAVÉ, 2005; TOZONI-REIS, 2007).

Dentre as diferentes formas de categorizá-la, optou-se para este estudo três concepções: a conservadora, de origem ambientalista, que apresenta vínculos afetivos do homem com a natureza, enfoque na valorização e na proteção ambiental; a pragmática, que busca a solução de problemas ambientais por meio da legislação estabelecida e a associação entre desenvolvimento econômico e sustentabilidade; e a crítica, de caráter interdisciplinar para o entendimento da problemática socioambiental, mudança de comportamento coletivo e a formação de sujeitos ecológicos (SILVA; CAMPINA, 2011).

A EA, em suas distintas facetas, pode ser encontrada em vários meios de comunicação, com objetivos de informar e sensibilizar o leitor ou o ouvinte sobre determinada situação. De acordo com Vieira e Henning (2012), a mídia tornou-se atualmente um importante veículo de propagação da EA entre a população, visando formar indivíduos com diferentes modos de ser e viver na contemporaneidade. Para tanto, a música é concebida como uma estratégia de ensino voltada à Educação Ambiental (MARIN; PEREIRA, 2009).

Em músicas locais e regionais é possível identificar trechos que enfatizam os problemas socioambientais, valorização da cultura, modo de vida amazônico e ideias preservacionistas/conservacionistas em relação aos recursos naturais (ALVES; PONTES, 2017). Diante disso, o objetivo deste estudo foi categorizar em três concepções - conservadora, pragmática e crítica - as músicas relacionadas à EA de artistas paraenses. 


\section{Concepções de Educação Ambiental: conservadora, pragmática e crítica}

A EA Conservadora reflete sobre os paradigmas da sociedade moderna, visando privilegiar ou promover o aspecto cognitivo do processo pedagógico, acreditando que ao transmitir o conhecimento correto o indivíduo compreenderá a problemática socioambiental, transformando a si próprio e a sociedade (MMA, 2004). Esta ideologia é originária de práticas ambientalistas, no contexto internacional, por isso tem como palavras-chave: natureza, conservação, proteção e destruição, além de que, praticamente, não aborda questões sociais e políticas, isto é, são apresentados apenas os problemas ambientais de forma superficial, desconsiderando as causas mais profundas (SILVA; CAMPINA, 2011).

Desta forma, é comum encontrar em ambientes escolares esta concepção de EA, pois é a de mais fácil compreensão, por se tratar de uma visão reducionista de observar e compreender o meio ambiente, porém, em opinião particular, deve ser a base para a promoção das ideias mais complexas, como a pragmática e a crítica, por exemplo. De acordo com Silva et al. (2013), a EA Conservadora é representada pelas atividades de contemplação da natureza, datas comemorativas e atividades de contato com a natureza. Neste cenário, as ações desenvolvidas têm por principal objetivo incutir em seus participantes a contemplação e a valorização ambiental e, em seguida, a adoção de práticas simples e sustentáveis para preservar/conservar a natureza ou determinado recurso natural.

Conforme Guimarães (2004), a concepção conservadora da EA tem alicerce numa visão de mundo em que a realidade é fragmentada, simplificada e reduzida, perdendo a riqueza e a diversidade da relação, afinal, o foco da prática pedagógica é no indivíduo (na parte) e na transformação de seu comportamento (educação individualista e comportamentalista). Ainda de acordo com o autor, a educação é uma relação e se dá no processo e não, simplesmente, no sucesso da mudança comportamental de um indivíduo.

No Brasil, sob influência da ditatura militar, ao se evitar a politização dos espaços educativos, a EA passou a ser uma ação governamental que primava pela dissociação entre 0 ambiental e 0 educativo-político, possibilitando a multiplicação de discursos ingênuos e naturalistas e a prática focada na sensibilização do "humano" perante o "meio natural", ambos desvinculados dos debates sobre modelos societários como um todo (LOUREIRO, 2004). Conforme este autor, a EA ganhou visibilidade como instrumento de finalidade exclusivamente pragmática, isto é, em programas e projetos voltados para a resolução de problemas enquadrados como ambientais e como mecanismo de adequação comportamental ao que genericamente chamou-se de "ecologicamente correto".

A EA Pragmática evidencia "que somos capazes de resolver problemas numa postura individual de ação, acarretando a transferência de responsabilidade da esfera pública para a dimensão subjetiva" (GRÜN, 1996). Por isso, resume-se em quatro palavras: mudança comportamental, técnica,

revista brasileira educação ambiental 
solução e desenvolvimento sustentável (SILVA; CAMPINA, 2011). Sua principal característica é a mudança de comportamento individual por meio da quantidade de informações e leis, que surgem como soluções prontas, além de que é exigido atitudes que devem ser efetivas e bem-sucedidas, em um curto espaço de tempo, para solucionar problemas socioambientais com resultados rápidos (SILVA et al., 2013).

Por sua vez, a EA Crítica tem por objetivo promover ambientes educativos de mobilização desses processos de intervenção sobre a realidade e seus problemas socioambientais, para que se possa, nestes ambientes, superar as armadilhas paradigmáticas e propiciar um processo educativo, onde educandos e educadores estejam se formando e contribuindo pelo exercício de uma cidadania ativa, na transformação da grave crise socioambiental que se vivencia atualmente (MMA, 2004). Neste contexto, é possível verificar que excede à ideia de natureza como espaço estético, de recursos disponíveis e para contemplação-proteção, a finalidade é construir cidadãos conscientes e atuantes, buscando entender os inúmeros fatores, de diferentes origens, que permeiam a relação homem versus natureza.

No contexto educacional, essa perspectiva propõe a constituição de uma ação educativa orientada para a transformação das estruturas econômicas, políticas e sociais vigentes, onde a mudança de comportamentos individuais é substituída pela construção de uma cultura cidadã e pela formação de atitudes ecológicas, o que supõe a formação de um sentido de responsabilidade ética e social (CARVALHO, 2004). Nesta dimensão, as palavras-chave são: subjetividade, interdisciplinaridade, atitudes, cidadania ativa, sociedades sustentáveis (SILVA; CAMPINA, 2011).

A EA Crítica busca a partir dos mesmos referenciais constitutivos da crise socioambiental, encontrar uma solução para o conflito, de forma crítica, o que para isso, torna-se necessário a construção do conhecimento por meio da interpretação da realidade pela interdisciplinaridade e uma visão ampliada (GUIMARÃES, 2004). No campo libertário, a EA apresenta-se em abordagens similares (emancipatória, crítica, popular, ecopedagógica, transformadora, entre outras), cujo mérito é de estimular o diálogo democrático, qualificado e respeitoso entre todos os educadores ambientais ao promover 0 questionamento às abordagens comportamentalistas, reducionistas ou dualistas no entendimento da relação cultura-natureza (LOUREIRO, 2004).

\section{As músicas (regionais paraenses) como instrumento de Educação Ambiental}

Ao longo dos tempos, a música passou por vários níveis de importância e transformações, fazendo parte inicialmente do cotidiano expressivo, comunicativo e religioso do homem, contribuindo fortemente também para a formação ética e social de alguns povos e assumindo a importante finalidade de construção do conhecimento do indivíduo (CARRARO, 2011). Da mesma forma, é sabido que a música é uma forma de criação e manifestação cultural 
presente em distintos espaços, configurando-se num processo identitário (NABAES, 2008).

Neste contexto, o Estado do Pará é conhecido mundialmente por seu vasto repertório, compositores e cantores renomados, que expressam por meio da música e poeticidade assuntos diversos, de temas cotidianos até aos mais relevantes sob a perspectiva de EA. De acordo com Pressler e Guinalz (2007), a música paraense se destaca pela variedade de artistas como Nilson Chaves, Lucinha Bastos, Sebastião Tapajós, Fafá de Belém, Leila Pinheiro, artistas de diferentes gêneros e estilos musicais, como: como carimbó, siriá e brega, entre outros, que envolvem desde o público erudito até o popular.

A música, por diferir por localidades, assuntos e contextos, pode ser usada no processo educativo, quando se trata de questões importantes para o bem-estar da sociedade, em coerência com a realidade local. Desta forma, particularizando os problemas socioambientais, Rodrigues e Colesanti (2008) relataram que o conteúdo visual, a música e o compartilhamento das informações entre os agentes do processo educacional que a hipermídia pode propiciar devem otimizar o processo de sensibilização e a identificação dos problemas ambientais, levando à reflexão sobre a urgência da mudança dos atuais padrões de uso e distribuição dos bens ambientais.

Neste aspecto, há de considerar a capacidade que a música tem em sensibilizar um sujeito que entoa ou apenas escuta um trecho musical (MARIN; PEREIRA, 2009), afinal, trabalhar as questões ambientais por meio de recursos (imagens, vídeos, músicas) se torna indispensável, pois não se atingirá a proposta de educação transformadora se não forem trabalhadas as emoções (SILVA, 2007). Daí a importância em utilizar os recursos já existentes e pertinentes à realidade como estratégia educativa, principalmente quanto à Educação voltada ao Meio Ambiente, numa abordagem interdisciplinar e de livre acesso entre o público de diferentes tipologias. Aliás, as músicas regionais paraenses têm potencial para disseminar e incutir nos ouvintes a essência da EA, uma vez que, em particular, descrevem a realidade de Belém, do Pará e da Amazônia.

\section{Metodologia}

Primeiramente, foi-se realizada uma revisão da literatura sobre o tema e, em seguida, optou-se por três concepções inerentes à EA distintas tocantes ao assunto: Conservadora, Pragmática e Crítica. Para tanto, teve-se como base o estudo de Silva e Campina (2011), uma vez que os mesmos propõem uma discussão sobre a questão ambiental a partir do uso dos meios de comunicação, sendo que, neste caso, foram consideradas as músicas regionais do Estado do Pará, que são canais de transmissão de ideias.

Posteriormente, optou-se por fazer o levantamento das músicas regionais de dois artistas paraenses: Nilson Chaves e Lucinha Bastos. Estes artistas apresentam fortes laços com a cultura regional, o que pode ser confirmado pela intensa produção fonográfica ao longo dos anos, além da 
apresentação de shows fortemente relacionados à cultura regional paraense. Além disso, os mesmos estão em plena atividade como compositores e cantores, disseminando o modo de vida, as lendas, a culinária, a biodiversidade, os conflitos socioambientais, ou seja, aspectos sociais, econômicos, ambientais e culturais do Pará.

O procedimento de coleta de dados ocorreu por meio de busca na discografia virtual dos dois cantores/compositores quanto às letras musicais relacionadas à EA. Em seguida, estas foram analisadas e categorizadas conforme as três concepções supracitadas, sendo utilizadas na discussão trechos pertinentes das músicas.

\section{Resultados e discussão}

Entre as músicas analisadas, classificaram-se 12 como EA Conservadora, uma vez que discorriam sobre a natureza em seus aspectos ambientais e estéticos, com intuito de incutir a contemplação e a conservação/preservação do meio natural nas pessoas. Neste estudo, observou-se que não apenas os elementos naturais (animais, frutas, floresta, chuva, praia, baía) foram mencionados, mas também o forte apelo cultural pelos cantos e danças paraenses (carimbó, lundú e siriá), patrimônio histórico (Ver-o-Peso, Estação das Docas), centros urbanos (Belém, São Luís), lendas amazônicas (Lenda do Boto, da Curupira e da Cobra-Grande), festas religiosas (Círio de Nazaré), times de futebol (Paysandu e Remo), comidas típicas (pato no tucupi, tacacá), dialeto (Pai d'égua), que são características da Região Norte do Brasil, em especial, do Estado do Pará (Quadro 1, próxima página).

Notou-se que o intuito foi demonstrar tais aspectos culturais e ambientais do Pará, da Amazônia Brasileira, que é formado por um povo heterogêneo, de diferentes culturas, etnias e gostos, de distintos patrimônios materiais e imateriais, a fim de que haja a valorização por parte dos ouvintes (conterrâneos ou não), além de despertar neles a preocupação pela proteção dessas particularidades. Assim como nas letras musicais do carimbó de Marapanim-PA, as composições podem fazer menção ao meio ambiente, cultura e EA, transmitindo aos ouvintes mensagens sobre a caracterização e a preservação/conservação do meio natural e cultural, associando dança, música e poeticidade (ALVES; PONTES, 2017), como canal de comunicação. Nesse caso, a poesia - transformada em música - é revestida de uma poeticidade inspirada no meio ambiente (MONTEIRO, 2012) e inclui aspectos da sociedade, pois ambos estão relacionados. 
Quadro 1: Músicas com características de EA conservadora.

\begin{tabular}{|c|c|c|}
\hline Não peguei o Ita & Pai d'égua & Sabor Açaí \\
\hline 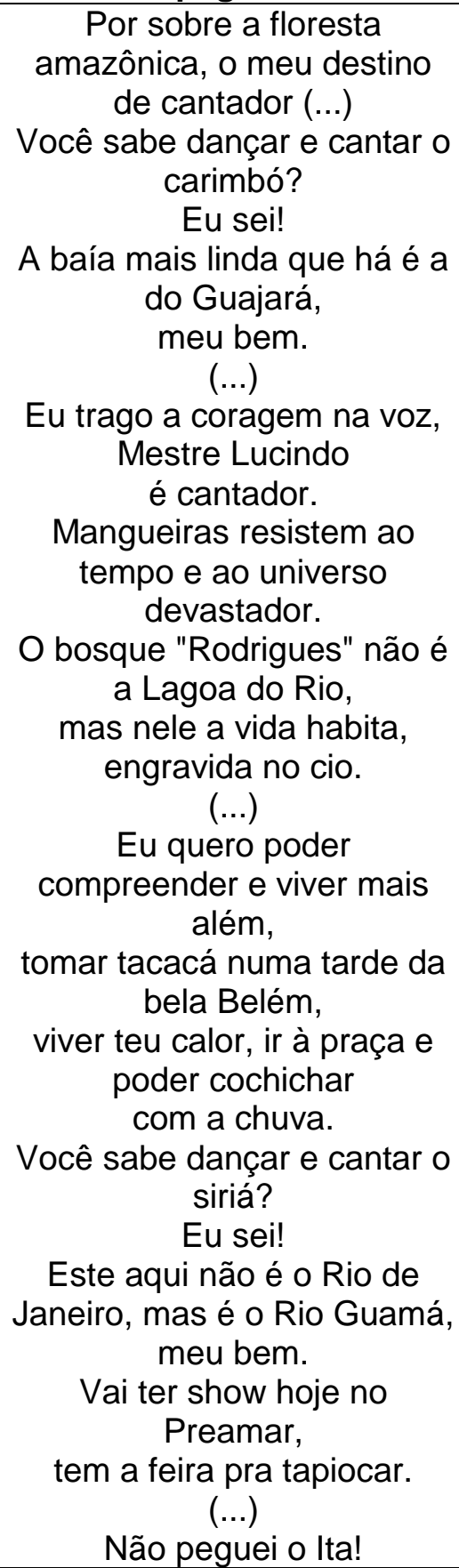 & $\begin{array}{c}\text { Quem não conhece o Pará, já } \\
\text { perdeu } \\
\text { Porque o que aconteceu } \\
\text { Num dia, no outro não tem } \\
\text { A gente basta parar para ver } \\
\text { Que é diferente e porque } \\
\text { Jamais se esquece Belém } \\
\text { Existe um termo chamado Pai } \\
\text { d'égua } \\
\text { (...) } \\
\text { Pai d'égua é dia de sol em } \\
\text { Mosqueiro } \\
\text { Salinas ou Marajó do outro lado } \\
\text { Pai d'égua é a rede é o vento é } \\
\text { o cheiro } \\
\text { Do Bacuri ou do Pato no Tucupi } \\
\text { caprichado } \\
\text { Pai d'égua é Remo e Paysandu } \\
\text { jogando } \\
\text { É o Círio de Nazaré na avenida } \\
\text { Pai d'égua é a moça que passa } \\
\text { flertando } \\
\text { Naquele quero-não-quero } \\
\text { Que é o gostoso da vida } \\
\text { LaLaLaia LaLaLaia } \\
\text { Quem vai ao Pará parou } \\
\text { Bebeu Açaí, por lá ficou }\end{array}$ & $\begin{array}{c}\text { E prá que tu foi plantado } \\
\text { E prá que tu foi plantada } \\
\text { Prá invadir a nossa mesa } \\
\text { E abastar a nossa casa... } \\
\text { (...) } \\
\text { A mais magra das palmeiras } \\
\text { Mas mulher do sangue grosso } \\
\text { E homem do sangue vasto } \\
\text { Tu te entrega até o caroço... } \\
\text { E tua fruta vai rolando } \\
\text { Para os nossos alguidares } \\
\text { Tu te entregas ao sacrifício } \\
\text { Fruta santa, fruta mártir } \\
\text { Tens o dom de seres muito } \\
\text { Onde muitos não têm nada } \\
\text { Uns te chamam açaizeiro } \\
\text { Outros te chamam juçara... } \\
\text { Põe tapioca } \\
\text { Põe farinha d'água } \\
\text { Põe açúcar } \\
\text { Não põe nada } \\
\text { Ou me bebe como um suco } \\
\text { Que eu sou muito mais que um } \\
\text { fruto } \\
\text { Sou sabor marajoara } \\
\text { Sou sabor marajoara } \\
\text { Sou sabor... (2x) }\end{array}$ \\
\hline
\end{tabular}

Continua... 
...continuação.

\begin{tabular}{|c|c|c|}
\hline Tô Belém & Destino Marajoara & Flor d'água \\
\hline $\begin{array}{c}\text { No meu corpo faz calor, } \\
\text { é sinal que vai chover. } \\
\text { Hoje tô minha cidade, } \\
\text { esperando por você. } \\
\text { (...) } \\
\text { O dia inteiro, o Peso aberto, } \\
\text { cheio de coisas pra você; } \\
\text { o feirante encantado } \\
\text { sempre pronto a lhe } \\
\text { atender. } \\
\text { Tome um pôster do } \\
\text { Mercado } \\
\text { pra nunca me esquecer, } \\
\text { prove os pratos variados } \\
\text { que ofereço pra você. } \\
\text { Hoje em mim é feriado, } \\
\text { na estação tudo é lazer. } \\
\text { Dê um pulo nos teatros } \\
\text { e me ouça com prazer } \\
\text { através dos meus cantores, } \\
\text { (...) } \\
\text { eu sou Mosqueiro, sou } \\
\text { carimbó, } \\
\text { índio moleque paraoara. } \\
\text { Círio de Nazaré, ilha do } \\
\text { Marajó, } \\
\text { Icoaraci, brega e marujada. } \\
\text { Sou Amazônia, eu sou RE X } \\
\text { PA! } \\
\text { sabor de fruta marajoara, } \\
\text { mestre Pinduca, Rui, } \\
\text { Waldemar, } \\
\text { Tôsitânia, Paraoara. } \\
\text { an só pra você. }\end{array}$ & $\begin{array}{c}\text { Quando me dei conta } \\
\text { Eu cantava Amazônia } \\
\text { Era um rio de beleza } \\
\text { Navegando em minha voz } \\
\text { O céu do Marajó } \\
\text { O canto do curió } \\
\text { Baía do Sol, quando dei por mim } \\
\text { Um curumim vibrava aqui } \\
\text { O coração de cantador, sorrir, aqui, } \\
\text { assim } \\
\text { Destino Marajoara (...) } \\
\text { Sina, sina, sina } \\
\text { Ajuruteua, Salinas } \\
\text { Tudo que aprendo me ensina } \\
\text { O prazer de te cantar } \\
\text { Sina, sina, sina } \\
\text { Luar de Mosqueiro fascina } \\
\text { A marujada me anima } \\
\text { Adoro o teu siriá } \\
\text { Quando fiz as malas } \\
\text { Pra correr o mundo } \\
\text { Mergulhei meus olhos } \\
\text { No fogo do teu calor } \\
\text { O límpido igarapé } \\
\text { O Círio de Nazaré } \\
\text { Alter do Chão, não fique distante } \\
\text { Não te esqueci nenhum segundo } \\
\text { Teu amuleto está no mundo } \\
\text { Em mim, aqui, assim (...) }\end{array}$ & $\begin{array}{c}\text { Praça da República } \\
\text { Praça Batista Campos } \\
\text { Nesses bancos } \\
\text { Sento sobre o meu } \\
\text { passado } \\
\text { Praça da República } \\
\text { Praça Batista Campos } \\
\text { Nesses bancos } \\
\text { Sonho com minha Cidade } \\
\text { Imagem, preguiça... } \\
\text { Mormaço, minha flor } \\
\text { d'água. } \\
\text { Paisagem bubuia } \\
\text { No tempo } \\
\text { Da minha flor d'água... } \\
\text { Venha mestre Verequete } \\
\text { Seu foguete lançado no } \\
\text { mar } \\
\text { Guamá, Guamá } \\
\text { Cupijó tá na proa contente } \\
\text { Seu setenta e Lucindo tão } \\
\text { lá, } \\
\text { Remar, remar... } \\
\text { Eu mergulho no rio da } \\
\text { m'ia gente } \\
\text { Desafogo e me dano a } \\
\text { cantar. }\end{array}$ \\
\hline
\end{tabular}

Continua... 
...continuação.

\begin{tabular}{|c|c|c|}
\hline Amazônia & Flor do Grão-Pará & Bom dia Belém \\
\hline $\begin{array}{l}\text { O curupira sim saiu de mim, } \\
\text { saiu de mim, saiu de mim... } \\
\text { Sei cantar o "tár" do } \\
\text { carimbó, do siriá e do lundú } \\
\text { O caboclo lá de Cametá e o } \\
\text { índio do Xingu } \\
\text { Tenho a força do muiraquitã } \\
\text { Sou pipira das manhãs } \\
\text { Sou o boto, igarapé } \\
\text { Sou rio Negro e Tocantins } \\
\text { Samaúma da floresta, } \\
\text { peixe-boi e jabuti } \\
\text { Mururé filho da selva } \\
\text { A boiúna está em mim. }\end{array}$ & $\begin{array}{c}\text { Sim, eu tenho a cara do Pará } \\
\text { O calor do carimbó } \\
\text { O uirapuru que sonha } \\
\text { Sou muito mais, } \\
\text { Eu sou, } \\
\text { Amazônia } \\
\text { Rosa flor vem plantar } \\
\text { mangueira } \\
\text { E o cheira-cheira do tacacá } \\
\text { Meu amor ata a baladeira } \\
\text { E balança a beira do rio mar } \\
\text { Belém, Belém acordou a feira } \\
\text { Que é bem na beira do } \\
\text { Guajará } \\
\text { Belém, Belém, menina } \\
\text { morena } \\
\text { Vem Ver-o-Peso do meu } \\
\text { cantar } \\
\text { Belém, Belém és minha } \\
\text { bandeira } \\
\text { És a flor que cheira do Grão } \\
\text { Pará } \\
\text { Belém, Belém do Pará } \\
\text { Natinga } \\
\text { Do bar do parque do bafafá } \\
\text { Bem-te-vi, sabiá, palmeira } \\
\text { Não dá baladeira } \\
\text { Deixa voar } \\
\text { Belém, Belém acordou a feira } \\
\text { Que é bem na beira do } \\
\text { Guajará } \\
\text { Belém, Belém, menina } \\
\text { morena }\end{array}$ & $\begin{array}{c}\text { (...) Onde anda meu povo, } \\
\text { meu rio, meu peixe, } \\
\text { Meu sol, minha rede, meu } \\
\text { tambatajá } \\
\text { A sesta, o sossego da tarde } \\
\text { descalça, } \\
\text { o sono suado do amor que } \\
\text { se dá } \\
\text { E o orvalho invisível na flor } \\
\text { se embrulhando } \\
\text { (...) } \\
\text { Procuro a lembrança da } \\
\text { infância na grama } \\
\text { Dos campos tranquilos do } \\
\text { meu Marajó } \\
\text { Belém minha terra, minha } \\
\text { casa, meu chão } \\
\text { Meu sol de janeiro a janeiro } \\
\text { a suar } \\
\text { Me beija, me abraça que } \\
\text { quero matar } \\
\text { A doída saudade que quer } \\
\text { me acabar } \\
\text { Sem círio da Virgem, sem } \\
\text { cheiro cheiroso } \\
\text { Sem a "chuva das duas " } \\
\text { que não pode faltar } \\
\text { Cochilo saudades na noite } \\
\text { abanando } \\
\text { Teu leque de estrelas, } \\
\text { Belém do Pará! }\end{array}$ \\
\hline
\end{tabular}

Continua... 
...continuação.

\begin{tabular}{|c|c|c|}
\hline La Amazon & Estrela da Mata & A força que vem das ruas \\
\hline $\begin{array}{c}\text { Eu sou brasileiro } \\
\text { brasileiro da Amazônia, } \\
\text { brasileiro sonhador, } \\
\text { sou brasileiro do Pará, } \\
\text { tenho o tempero } \\
\text { de Belém, } \\
\text { eu tenho o cheiro, } \\
\text { sou norte com muito amor (2x). } \\
\text { Brasileiro, batuqueiro, } \\
\text { marabaixo, Macapá, } \\
\text { sou garantido, caprichoso, boi- } \\
\text { bumbá, } \\
\text { sou Rio Branco, Porto Velho, } \\
\text { Boa Vista,, } \\
\text { pororoca, carimbó, marajoara, } \\
\text { eu sou nortista, } \\
\text { meu coração bate palmas no } \\
\text { Tocantins, } \\
\text { de repente eu troco passo e já } \\
\text { estou no Maranhão } \\
\text { dançando reggae-boi em São } \\
\text { Luís, } \\
\text { na ilha do amor, } \\
\text { dançando reggae-oi em São } \\
\text { nuís } \\
\text { na ilha do amor } \\
\text { (...) }\end{array}$ & 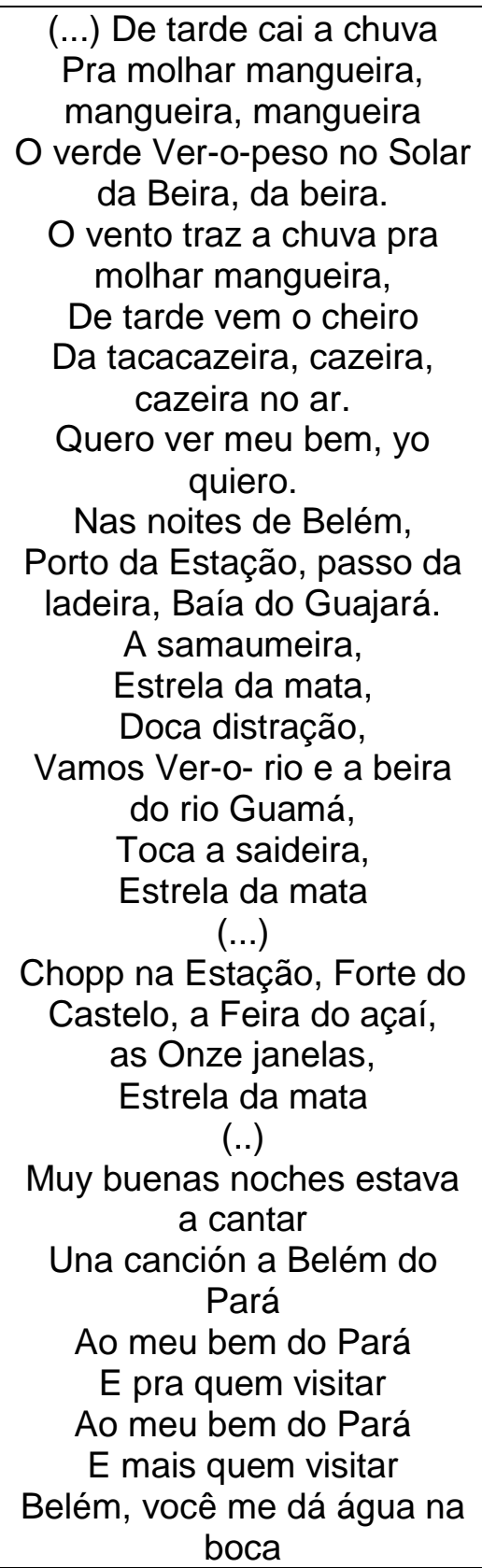 & $\begin{array}{c}\text { Belém, Belém, Belém } \\
\text { Será que tá tudo bem } \\
\text { Belém, Belém, Belém } \\
\text { Será que tá } \\
\text { Tudo bem, tudo bem } \\
\text { A música na praça } \\
\text { O boi fazendo graça } \\
\text { É Ronaldo e seus meninos } \\
\text { Ensinando a nação } \\
\text { Que o futuro tá no centro da } \\
\text { cultura } \\
\text { Da cultura popular, popular } \\
\text { E taca carimbó } \\
\text { De Pinduca, de Lucindo, Cupijó } \\
\text { Verequete, pavulagem } \\
\text { Dos meninos Eduardo, Taynara e } \\
\text { Cavalero } \\
\text { Vão tocar no preamar, preamar } \\
\text { O couro treme a terra } \\
\text { De Fabico, de setenta } \\
\text { Malhadinho de bandeira } \\
\text { Seu Rufino, seu Joaquim } \\
\text { Laurentina muito linda quando } \\
\text { canta } \\
\text { Dá vontade de chorar, de chorar } \\
\text { O grande capitão } \\
\text { Nos boca-de-ferro } \\
\text { Da Pedreira, Marambaia } \\
\text { Terra-Firme, Sacramenta } \\
\text { Marituba, Ananindeua, Icoaraci, } \\
\text { do Benguí, pro Guamá, Pro } \\
\text { Guamá }\end{array}$ \\
\hline
\end{tabular}

Fonte: Autoria própria. 
Em relação à EA Pragmática contida nas letras musicais analisadas, verificou-se que há apenas resquícios dessa concepção, com pouca frequência, uma vez que foram classificados apenas dois trechos de músicas (Quadro 2). Um deles discorre sobre os rios, Guamá e Tocantins, e o desmatamento como um problema ambiental que tende a afetar a dinâmica desses corpos hídricos, e assim enfatizou: "não matem o mato inteiro" para que "não morra o Rio Guamá". Outro trecho: "Rosa flor, vem plantar mangueira", ao considerar o contexto da composição, correspondeu a adoção de uma postura individual que visa o (re)conhecimento, a valorização e o apreço pelo modo de vida do povo belenense (Quadro 2). No entanto, essas músicas não mencionaram normas e leis já existentes que visam mudanças de comportamento individual e coletivo para solucionar os problemas socioambientais. De acordo com Crespo (1998) e Silva e Campina (2011), a EA Pragmática apresenta o foco na ação, na busca de soluções para as questões ambientais e na suposição de normas a serem adotadas, pois tem suas primícias no movimento ambientalista pragmático.

Quadro 2: Músicas com características de EA Pragmática.

\begin{tabular}{|c|c|}
\hline Toca Tocantins & Flor do Grão-Pará \\
\hline Toca Tocantins & $(. .)$. \\
Tuas águas para o mar & Rosa flor vem plantar mangueira \\
É lá o teu destino & E o cheira-cheira do tacacá \\
Aqui não é teu lugar & Meu amor ata a baladeira \\
Que viva o açaizeiro & E balança a beira do rio mar \\
A arara e o tamuatá & Belém, Belém acordou a feira \\
Não matem o mato inteiro & Que é bem na beira do Guajará \\
Não morra o rio Guamá & Belém, Belém, menina morena \\
Toca Tocantins & Vem Ver-o-Peso do meu cantar \\
Tuas águas para o mar (...) & Belém, Belém és minha bandeira \\
\hline
\end{tabular}

Fonte: Autoria própria.

Considerando a EA Crítica, foram classificadas cinco músicas, as quais refletiam sobre a realidade subumana de pessoas sem teto - vulgo, moradores de rua -, inclusive crianças, que vivem em condições de miséria e marginalizadas, assim como a falta de sensibilização das pessoas que as discriminam; quanto à criminalidade, que atinge a cidade de Belém e seus pontos turísticos, como o Ver-o-Peso, uma situação complexa que envolve "vida, sonho e medo, lama, fama, fome, riso e dor" (Quadro 3). Da mesma forma, tais músicas discorriam sobre a cultura nortista, geralmente, numa visão distorcida por outras regiões, desvalorizada por muitos, vista apenas como povoado de índios canibais: "nossos índios não comem ninguém", e como fonte de recursos exploráveis, bem como à ruptura de costumes e tradições a partir da miscigenação ou adesão de outras culturas: "agora é só hambúrguer"; também retrata sobre assuntos ambientais, como a destruição da camada de ozônio, que afeta o equilíbrio da natureza e o bem-estar humano, que é um tema discutido desde a Revolução Industrial em busca de soluções para "que a vida não tenha final" (Quadro 3).

revista brasileira educação ambiental 
Quadro 3: Músicas com características de EA Crítica.

\begin{tabular}{|c|c|c|}
\hline Tudo manga & Um bicho nas ruas & Belém, Pará, Brasil \\
\hline $\begin{array}{c}\text { Sob a chuva da cidade um } \\
\text { moleque sai pulando } \\
\text { Short velho encardido, } \\
\text { pelas ruas vai correndo } \\
\text { Vai pequeno, vai moleque. } \\
\text { Cheio de sonho e virtude } \\
\text { Abre a mão e apara a } \\
\text { manga, orgulhoso feito um } \\
\text { Conde } \\
\text { Sem querer de tudo manga } \\
\text { faz caretas e amiúde } \\
\text { Ao homem que o } \\
\text { repreenda e que condene } \\
\text { sua atitude } \\
\text { Traz a fome no semblante, } \\
\text { seus olhinhos de moleque } \\
\text { Brilham mais que } \\
\text { diamante, mesmo assim } \\
\text { mostra saúde } \\
\text { Ôoo ôoo Pros homens tá } \\
\text { tudo mal } \\
\text { Ôoo ôoo Pra ele tá tudo } \\
\text { manga } \\
\text { Joga pedra na mangueira, } \\
\text { erra e acerta na vidraça } \\
\text { Desembesta na carreira, } \\
\text { grita o PM na praça } \\
\text { Sempre sai pela tangente e } \\
\text { escapole da mulher } \\
\text { Vai tocando as campainhas } \\
\text { das mansões de Nazaré } \\
\text { Sempre que volta pra casa } \\
\text { pula o muro do sobrado } \\
\text { Dá-lhe um tapa no jambeiro } \\
\text { e é taxado de atentado } \\
\text { Traz a fome no semblante, } \\
\text { seus olhinhos de moleque } \\
\text { Brilham mais que } \\
\text { diamante, mesmo assim } \\
\text { mostra saúde } \\
\text { Moleque se tu soubesses o } \\
\text { quanto eu lembro de mim } \\
\text { Te Vendo de boca suja } \\
\text { chupando manga assim. }\end{array}$ & $\begin{array}{l}\text { Eu nunca vi um cavalo, } \\
\text { galinha, cabrito e gado } \\
\text { qualquer outro animal } \\
\text { nas ruas abandonado } \\
\text { No entanto aí vem o bicho } \\
\text { andando entre os automóveis } \\
\text { sem que ninguém Ihe olhe } \\
\text { nos grandes olhos imóveis } \\
\text { Ninguém Ihe dá de comer } \\
\text { nem lhe leva a passear } \\
\text { Ninguém lhe lava os pelos } \\
\text { ninguém o quer afagar } \\
\text { como se afaga um cão } \\
\text { ou se joga milho aos pombos } \\
\text { Tem dois olhos, duas mãos } \\
\text { e às vezes no peito um } \\
\text { bumbo. } \\
\text { Tem dois olhos, duas mãos } \\
\text { Pode escrever a llíada } \\
\text { Pode sentir saudade } \\
\text { Pode ganhar Olimpíada } \\
\text { Pode morrer na cruz } \\
\text { Pode até pisar na lua, } \\
\text { Dentro dele mora a luz } \\
\text { Igual a minha e a tua. } \\
\text { É mais que um mico-leão } \\
\text { bem maior que uma baleia } \\
\text { nele habita o sim e o não. } \\
\text { Nele uma luz se ateia } \\
\text { Luz humana que incendeia } \\
\text { não que ilumina seu sonho, } \\
\text { Em um súbito se ateia } \\
\text { um sentimento medonho, } \\
\text { Sentimento que clareia seus } \\
\text { grandes olhos imóveis, } \\
\text { Terrível dor que passeia a } \\
\text { noite entre os automóveis. } \\
\text { Oh oh oh! o bicho nas ruas } \\
\quad \text { (...) }\end{array}$ & $\begin{array}{c}\text { Vão destruir o Ver-o-Peso e } \\
\text { construir um shopping center } \\
\text { Vão derrubar o Palacete Pinho pra } \\
\text { fazer um condomínio } \\
\text { Coitada da Cidade Velha que foi } \\
\text { vendida pra Hollywood } \\
\text { Pra ser usada como um albergue } \\
\text { num novo filme do Spielberg } \\
\text { Quem quiser venha ver } \\
\text { Mas só um de cada vez } \\
\text { Não queremos nossos jacarés } \\
\text { Tropeçando em vocês } \\
\text { A culpa é da mentalidade } \\
\text { Criada sobre a região } \\
\text { Por que que tanta gente teme? } \\
\text { Norte não é com "M" } \\
\text { Nossos índios não comem ninguém } \\
\text { Agora é só hambúrguer } \\
\text { Por que ninguém nos leva a sério? } \\
\text { Só o nosso minério? } \\
\text { Quem quiser venha ver } \\
\text { Mas só um de cada vez } \\
\text { Não queremos nossos jacarés } \\
\text { Tropeçando em vocês } \\
\text { Aqui a gente toma guaraná quando } \\
\text { não tem coca-cola } \\
\text { Chega das coisas da terra que o que } \\
\text { é bom vem lá de fora } \\
\text { Transformados até a alma sem } \\
\text { cultura e opinião } \\
\text { O Nortista só queria fazer parte da } \\
\text { nação } \\
\text { Ah, chega de malfeituras } \\
\text { Ah, chega de triste rima } \\
\text { Devolvam a nossa cultura } \\
\text { Queremos o Norte lá em cima } \\
\text { Porque, onde já se viu? } \\
\text { Isso é Belém } \\
\text { Isso é Pará } \\
\text { Isso é Brasil }\end{array}$ \\
\hline
\end{tabular}

Continua... 
...continuação;

\begin{tabular}{|c|c|}
\hline O sonho de Xamã & Os pregões \\
\hline Muito tempo depois deste sonho, & $(\ldots)$ \\
A ciência pode então descobrir, & Olha ali, lá vai um ladrão \\
Que o buraco na camada de ozônio, & Olha o rapa vai te prender \\
É por onde o céu pode cair & Olha o rapa vai te prender \\
Isso é o Ver-o-peso \\
Que a vida não tenha final & E tudo tem por cá \\
Que o xamã não desapareça & Vida, sonho e medo \\
Que o sonho não seja real & Lama, fama, fome, riso e dor \\
\end{tabular}

Fonte: Autoria própria.

Toda criação artística, como a música, em particular, é uma manifestação e expressão do homem, podendo ser influenciada por aspectos sociais, políticos, econômicos, culturais e de relações humanas, e por isso é um campo privilegiado para abordar questões e temas importantes do dia-a-dia (VIEIRA; HENNING, 2012) e, ultimamente, estando sendo usada em processos educativos. No contexto educacional, é sugerível a constituição de uma ação educativa orientada para a transformação das estruturas econômicas, políticas e sociais vigentes (REIGOTA, 1995), visando respostas aos problemas socioambientais, em sua complexidade. A concepção crítica de $E A$, que é mais elaborada, também foi encontrada em composições de Carimbó considerando aspectos políticos, éticos, sociais e ambientais, levando o ouvinte à criticidade sobre os problemas vigentes na sociedade (ALVES; PONTES, 2017).

\section{Conclusões}

As músicas regionais quando relacionadas à EA podem caracterizar a natureza, nos seus aspectos naturais e humanos, e incutir a contemplação natural e cultural; enfatizar mudanças de mentalidades e ações para solucionar problemas vigentes; e até expressar assuntos mais complexos, como a exclusão e vulnerabilidade sociais, uma vez que os cantores/compositores estão mais próximos da realidade e assim têm mais propriedade para transmitir os fatos ocorridos em forma de poesia e música.

A socialização da EA, em suas várias concepções, é facilitada por intermédio dessas músicas, permitindo o leitor/ouvinte a (re)conhecer os elementos naturais, humanos e culturais de uma determinada região, bem como os problemas socioambientais, suas causas e efeitos, e até um posicionamento crítico e atuante diante da problemática socioambiental em que está inserido.

Diante disso, as músicas regionais são propostas pedagógicas que podem ser trabalhadas, de forma interdisciplinar, objetivando a sensibilização das pessoas acerca de sua realidade local e regional. Então, trabalhar as concepções de EA com músicas regionais é uma forma de associar Educação,

revista brasileira educação ambiental 
Meio Ambiente, Cultura e Interdisciplinaridade, com o intuito de formar cidadãos conscientes, críticos e atuantes na relação sociedade-natureza.

\section{Referências}

ALVES; R.J.M.; PONTES, A.N. A cultura, o meio ambiente e a educação ambiental nas letras musicais do carimbó de Marapanim (PA). Revista Brasileira de Educação Ambiental, São Paulo, v. 12, n. 1, p. 155-164, 2017.

BRASIL. Lei no 9.795 de 27 de abril de 1999. Dispõe sobre a Educação Ambiental, institui Política Nacional de Educação Ambiental e dá outras providências. Brasília: Diário Oficial da União, 1999. Disponível em: < http://www.planalto.gov.br/ccivil_03/leis/L9795.htm>. Acesso em: 15 jun. 2017.

CARRARO, C. Música e educação - o contrabaixo e a bossa: uma perspectiva histórica e prática. Projeto Passo fundo, 2011.

CRESPO, S. Educar para a sustentabilidade: a educação ambiental no programa da Agenda 21. In: NOAL, F. O.; REIGOTA, M.; BARCELOS, V. H. L. Tendências da Educação Ambiental Brasileira. Santa Cruz do Sul: EDUNISC, 1998. 211-225p.

GUIMARÃES, M. Educação Ambiental Crítica. In: LAYRARGUES, P.P. Identidades da Educação Ambiental Brasileira. Brasília: Ministério do Meio Ambiente, 2004. 25-34p.

GRÜN, M. Ética e educação ambiental: uma conexão necessária. Campinas: Papirus, 1996.

HENRIQUES, R. et al. Marcos Institucionais. In: Educação ambiental; Aprendizes de sustentabilidade. Secretaria de Educação Continuada, alfabetização e diversidade, 2007. 12-19p.

LOUREIRO, C.F.B. Educação ambiental e movimentos sociais na construção da Cidadania ecológica e planetária. In: LOUREIRO, C F.B.; LAYRARGUES, P.P.; CASTRO, R.S. (Orgs.) Educação Ambiental: repensando o espaço da cidadania. $2^{\mathrm{a}}$ ed. São Paulo: Cortez, 2002.

LOUREIRO, C.F.B. Educar, participar e transformar em educação ambiental. Revista Brasileira de Educação Ambiental, p. 13-20, 2004.

MARIN, A.A.; PEREIRA, C.A. Sons, corpo, sensibilização: diálogos entre a música e a Educação Ambiental. Revista Eletrônica do Mestrado de Educação Ambiental, Rio Grande, v. 22, n. 1, p. 401-416, 2009.

MINISTÉRIO DO MEIO AMBIENTE - MMA. Identidades da educação ambiental brasileira, 2004. 156p.

MONTEIRO, V.P. Tambores da floresta: o estudo da performance do tambor carimbó no carimbó de Salinópolis, no Estado do Pará. In: Simpósio Brasileiro de Pós-Graduandos em Música, Anais, Rio de Janeiro, v. 2, n. 2, p. 934-944, 2012. 
NABAES, T.O. Natureza social e apreciação musical: considerações. Revista Eletrônica do Mestrado de Educação Ambiental, Rio Grande, v. 21, n. 2, p. 217-226, 2008.

PRESSLER, N.G.S.; GUINALZ, J.P. O brega paraense: as modificações da cultura popular no espaço urbano. In: XII encontro da associação Nacional de Pós-Graduação e Pesquisa em Planejamento Urbano e Regional, Anais... 2007.

REIGOTA, M. Meio ambiente e representação social. São Paulo: Cortez, 1995.

RODRIGUES, G.S.S.C.; COLESANTI, M.T.M. Educação ambiental e as novas tecnologias de informação e comunicação. Sociedade \& Natureza, Uberlândia, v. 20, n. 1, p. 51-66, 2008.

SAUVÉ, L. Educação Ambiental: possibilidades e limitações. Educação e Pesquisa, v. 31, n. 2, p. 317-322, 2005.

SILVA, R.L.F. O meio ambiente por trás da tela - estudos das concepções de educação ambiental dos filmes da TV Escola. Tese (Doutorado em Educação), Programa de Pós-graduação em Educação, USP, São Paulo, 2007. Disponível em: <http://www.teses.usp.br/teses/disponiveis/48/48134/tde-25042007104315/en.php>. Acesso em: 15 jun. 2017.

SILVA, R.L.F.; CAMPINA, N.N. Concepções de educação ambiental na mídia e em práticas escolares: contribuições de uma tipologia. Pesquisa em Educação Ambiental, v. 6, n. 1, p. 29-46, 2011.

SILVA, L.M.; BATALHA, S.S.A.; HORA, N.N.; PONTES, A.N. Educação ambiental a partir da valorização da cultura regional do estado do Pará. Revista Eletrônica do Mestrado de Educação Ambiental, Rio Grande, v. 30, n. 2, p. 290-303, 2013.

SORRENTINO, M. De Tbilisi a Thessaloniki, a Educação Ambiental no Brasil. In: CASCINO, F.; JACOBI, P.; OLIVEIRA, J.F. (Org.). Educação, Meio Ambiente e Cidadania: reflexões e experiências. Secretaria de Estado do Meio Ambiente/Coordenadoria de Educação Ambiental. São Paulo: 1998. p. 27-32.

TOZONI-REIS, M.F.C. Contribuições para uma pedagogia crítica da Educação Ambiental: reflexões teóricas. In: LOUREIRO, C.F.B. (Org.). A questão ambiental no pensamento crítico: natureza, trabalho e educação. Rio de Janeiro: QUARTET, 2007. p. 177-219.

VIEIRA, V.T.; HENNING, P.C. Atravessamentos culturais e crise ambiental na atualidade: modos ecológicos de vida no rock' n roll. Revista Eletrônica do Mestrado de Educação Ambiental, Rio Grande, v. 28, n. 1, p. 434-448, 2012. 